\title{
The use of extension tubes in thermography
}

by M. Kaluza*, B. Wiecek and G. De Mey**

\begin{abstract}
*Institute of Electronics, Technical University of Lodz, Wolczanska 211/215, 90-924 Lodz, Poland, mkaluza@poczta.onet.pl, wiecek@p.lodz.pl

${ }^{* * D e p a r t m e n t}$ of Electronics and Information Systems, University of Ghent, Sint Pietersnieuwstraat 41, 9000 Ghent, Belgium, demey@elis.ugent.be
\end{abstract}

\section{Abstract}

For close up or microscopic measurements in infrared thermography, one can use special designed lenses which are normally put in front of the standard fixed on the thermographic camera. If this standard lens can be unscrewed from the camera, another and much cheaper possibility exist: using extension tubes so that the standard lens is further away from the detector. One is then able to focus on much smaller objects. In this paper some drawbacks of this method will be investigated experimentally and explained theoretically as well [1].

\section{Introduction}

Macro photography is a domain, where the size of the images projected the "film" plane (i.e. film or digital detector matrix) have dimensions close to the size of the object. Several solutions are used. Once can use a lens specially designed for close up work, called a macro lens. Other solutions are attaching extension tubes or a continuous adjustable bellow between the lens and the camera, without any additional optical components between the camera and the lens. The only purpose is to increase the distance between the lens and the "film" plane in order to obtain larger images.

When using infrared thermography in microelectronics or materials science research, one has often the need for imaging objects with sizes comparable to the detector matrix pixel pitch. The use of extension tubes used in macro photography will now be investigated for thermographic purposes $[2,6]$.

The measurements were made using a MWIR Cedip Titanium camera with cooled InSb matrix detector having $640 \times 512$ pixels each having a pitch of $15 \mu \mathrm{m}$.

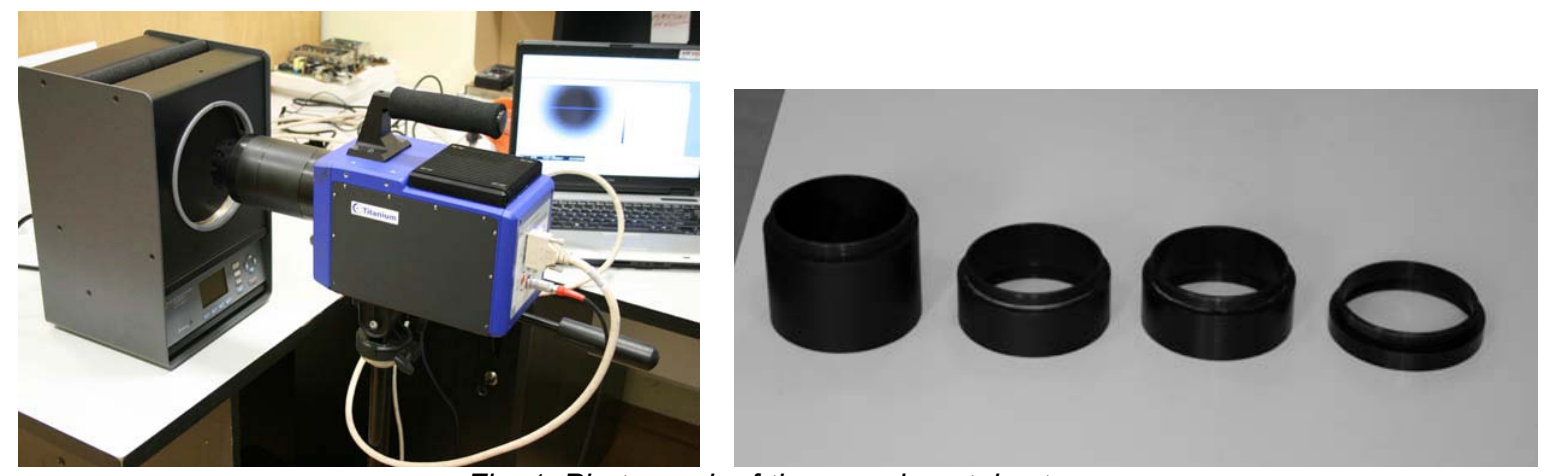

Fig. 1. Photograph of the experimental setup

The standard lens has a focal length of $F=50 \mathrm{~mm}$ with a maximum diaphragm of 2. 4 extension tubes were available with lengths $12 \mathrm{~mm}$ (tube 1), $30 \mathrm{~mm}$ (tube 2), $30 \mathrm{~mm}$ (tube 3) and 60mm (tube 4).

All tubes were anodized. Using a Fluke 4181 precision infrared calibrator as a black body reference source all possible combinations of the extension tubes could be analyzed. A photograph is shown in fig. 1. An overview of all possible combinations with the extension tubes is shown in the table below.

Table 1. Extension tubes configurations

\begin{tabular}{|l|c|c|c|c|c|c|c|c|c|c|}
\hline Extension tube & none & 1 & 2 & $1+2$ & 4 & $1+4$ & $2+4$ & $1+2+4$ & $2+3+4$ & $1+2+3+4$ \\
\hline $\begin{array}{l}\text { Total length } \\
{[\mathrm{mm}]}\end{array}$ & 0 & 12 & 30 & 42 & 60 & 72 & 90 & 102 & 120 & 132 \\
\hline $\begin{array}{l}\text { Lens to black } \\
\text { body distance } \\
{[\mathrm{cm}]}\end{array}$ & $\begin{array}{c}\text { min. } \\
\text { Resolution }\end{array}$ & 21,5 & 10,8 & 7,5 & 5,5 & 4,5 & 3,9 & 3,5 & 3,1 & 2,8 \\
\hline \begin{tabular}{l} 
[ $\mathrm{mm} /$ pixel] \\
\hline
\end{tabular} & 88 & 44 & 22 & 17 & 13 & 11 & 9 & 8 & 7 & 6 \\
\hline
\end{tabular}




\section{Experimental results for a black body at $80^{\circ} \mathrm{C}$}

If the camera is positioned in front of the black body at a uniform temperature $\left(80^{\circ} \mathrm{C}\right.$ in our experiments), all pixels should indicate exactly the same temperature. If extension tubes were inserted quite different results have been obtained as shown in fig. 2.

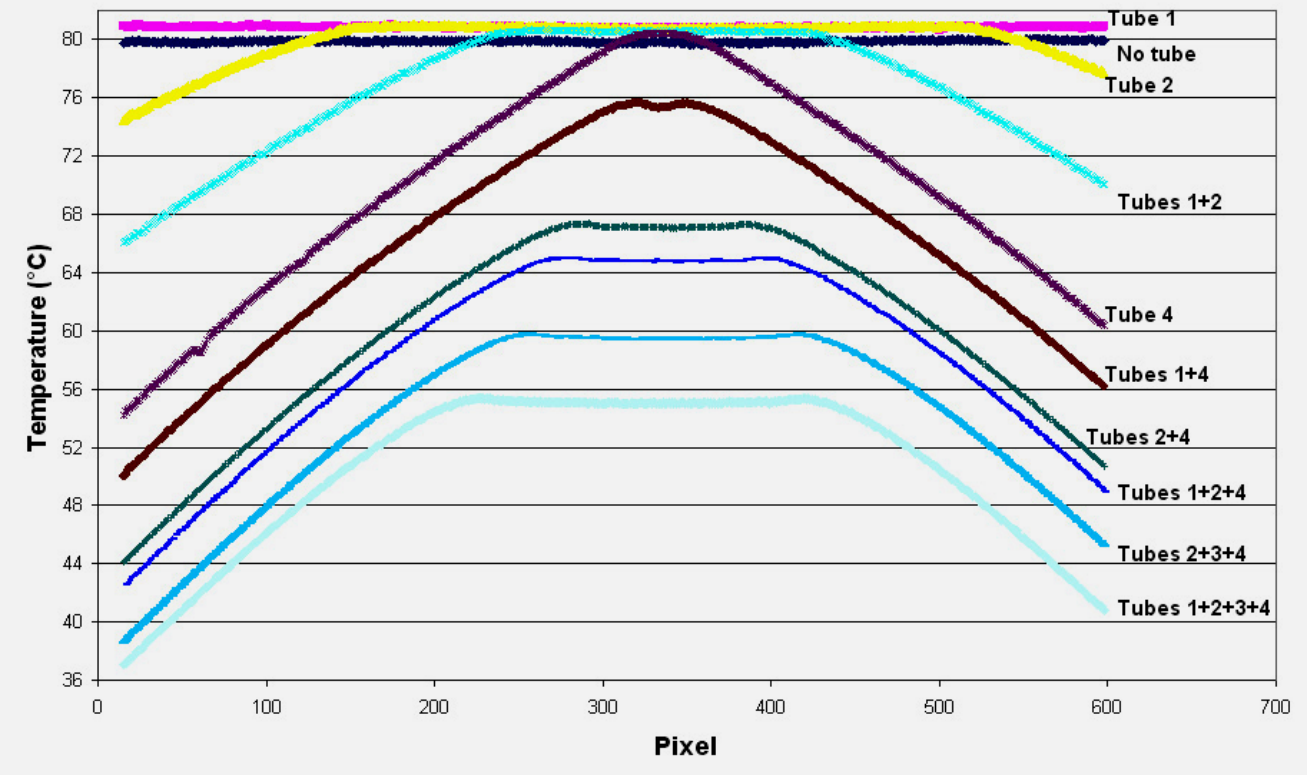

Fig. 2. Experimental results for a black body at $80^{\circ} \mathrm{C}$ horizontal line.

The central pixel (320) is located on the optical axis and the image displays the readout temperatures along a

Two phenomena are clearly observed in fig. 2. First of all, the temperature recorded by the central pixel decreases if too many tubes are inserted. If the 4 tubes are used, with a total length of $132 \mathrm{~mm}$ the temperature readout has dropped to $55^{\circ} \mathrm{C}$ much lower than the right value $80^{\circ} \mathrm{C}$. A second peculiar phenomenon arises when the pixels are a bit further away from the optical axis. The readout temperature is even more reduced, although all these pixels were in the field of view.

\section{Physical explanation of the results at $80^{\circ} \mathrm{C}$}

In order to understand the results shown in fig. 2, it must be made clear that the supplier of the camera designed a lens for normal use, which means there is no guarantee the readout temperatures will still be correct is the used is inserting own made tubes not designed by the supplier. It should be remarked that only the $12 \mathrm{~mm}$ tube was made by the supplier.

The objective of the camera is composed of two lenses, the front lens having a diameter of $45 \mathrm{~mm}$, the back lens being smaller with a diameter of only $34 \mathrm{~mm}$. If an object is at a long distance, all the infrared light will be focused towards the detector as indicated schematically in fig. $3 a$.

If extension tubes are used, the object is closer to the front lens whereas the detector is further away (fig. 3b). The back lens having a smaller diameter, a part of the light collected by the front lens is no longer falling on the back lens and hence not focused toward the detector. This is indicated in fig. $3 \mathrm{~b}$ by the shaded area. Hence the readout temperature generated by the detector will be reduced.

If the infrared light is coming from an object not located on the optical axis, the above mentioned phenomenon will be even more pronounced as depicted schematically in fig. 3c. This explains the decay shown in fig. 2 for pixels not on the optical axis [3-5]. 


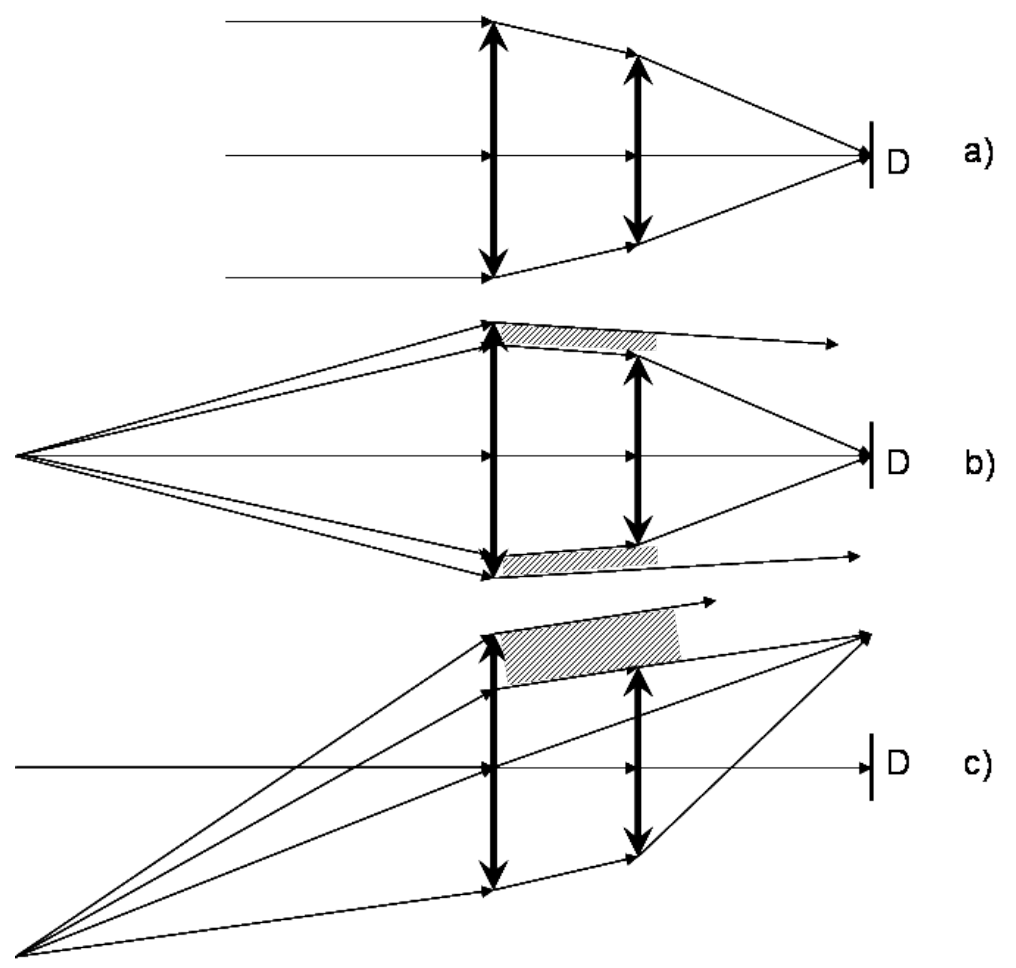

Fig. 3. Schematic view of infrared light propagation with and without tubes

\section{Experimental results for a black body at room temperature}

Similar measurements have been carried out when the black body was set to room temperature $\left(21^{\circ} \mathrm{C}\right)$. The results are shown in fig. 4.

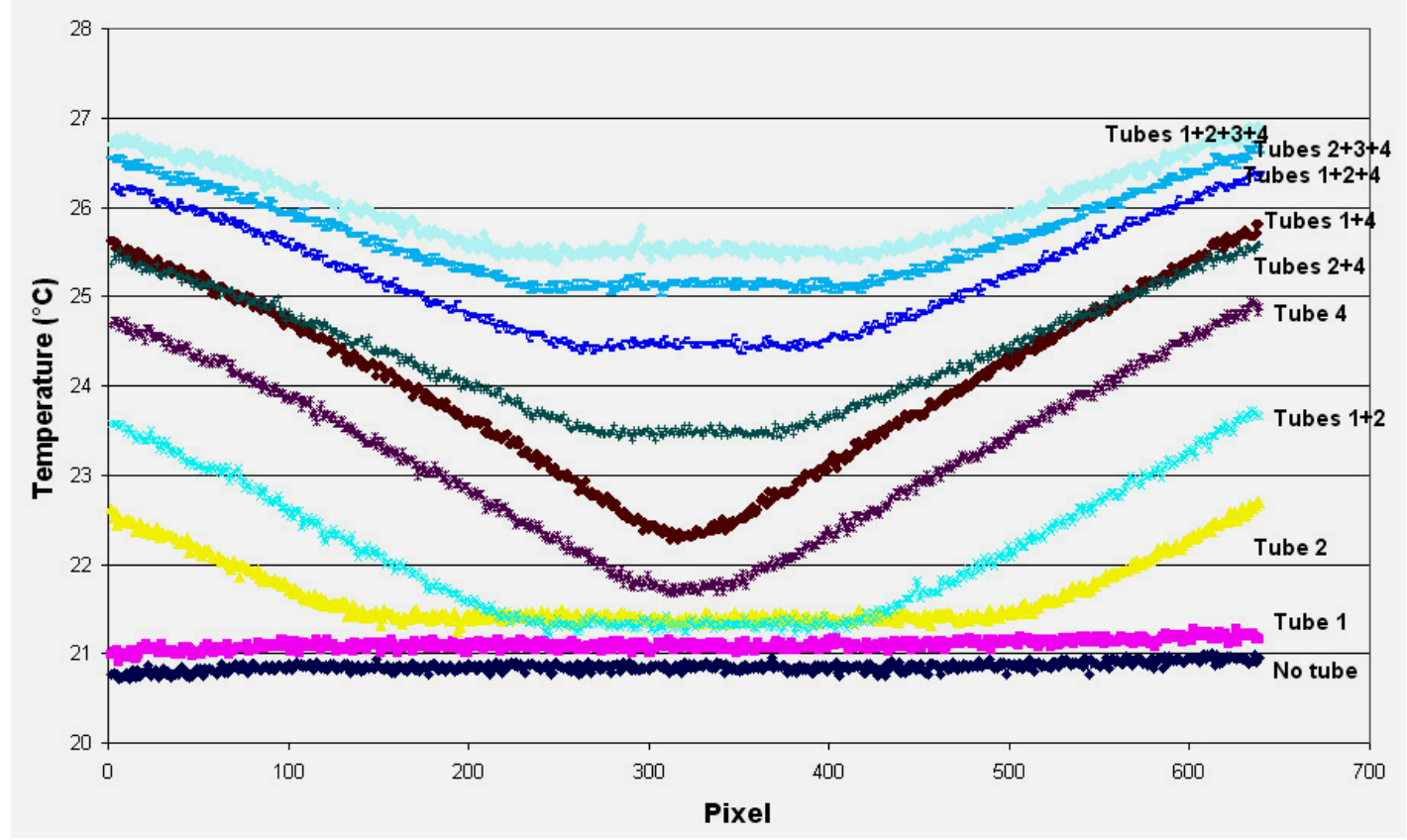

Fig. 4. Experimental results for a black body at room temperature

Quite strange results are observed. For the pixel on the optical axis the temperature raises the more tubes are inserted. With 4 extension tubes, the readout temperature was even as high as $\left(26^{\circ} \mathrm{C}\right)$, although no object above room temperature was put in front of the camera. For the other pixels, the temperature rise could even be higher.

A first comparison between fig. 2 and fig. 4 gives us the impression that the same physical phenomenon behind is responsible for both results, because both sets of curves look similar. However this time the explanation is 
more obvious. The infrared camera contains a lot of electronic circuits which dissipated a lot of power giving rise to excessive heating of the camera housing. It was observed that also the front part of the camera where the lens is screwed on, was heated as well. As a consequence, the tubes will be heated by conduction. Hence the detector gets extra parasitic radiation from the internal walls of the tubes, being heated above room temperature. The camera not being designed to take this extra radiation into account, a higher readout temperature will be the consequence. It is easy to understand that for the pixels not on the optical axis, this parasitic effect will be more pronounced.

A tube was cooled for some time before being mounted on the thermographic camera. The curves obtained then were completely different: the shape was the same as in fig. 2. After some time the tubes gets heated by the camera housing and the curves of fig. 4 were then obtained again.

The time evolution of the readout temperature of two pixels during this experiment is shown in fig. 5 .

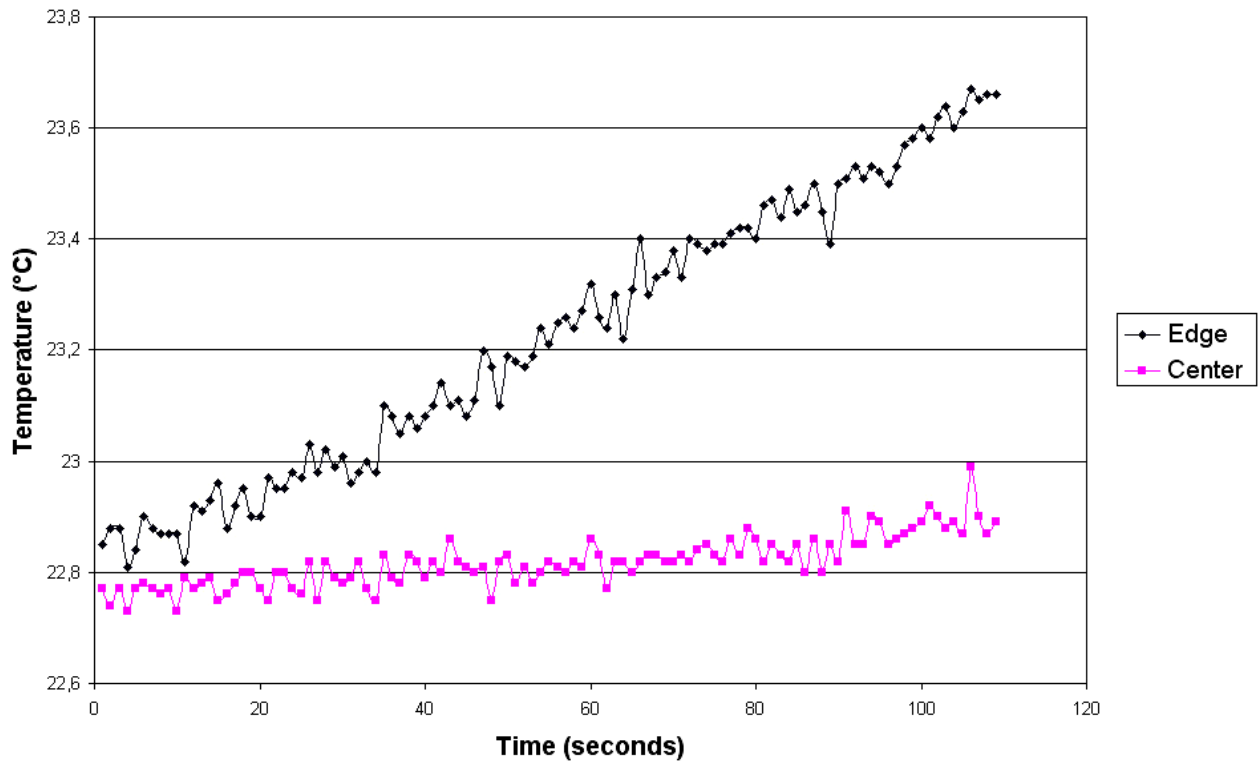

Fig. 5. Time evolution of the temperature of two pixels

\section{Conclusions}

Extension tubes remain a very interesting tool to use a thermographic camera for close up and microscopic experiments. The main advantage is these tubes are very cheap as compared to additional lenses. But one has to bear in mind the camera has been designed for a well defined and limited field of view. Hence one should carry out measurements with a black body in order to detect the geometrical optics effects caused by the extension tubes. Last but not least, one should verify the tubes are not heated by the electronic components packed densely inside the camera housing.

\section{REFERENCES}

[1] W. Minkina, S. Dudzik, Infrared thermography - errors and uncertainties, Wiley and Son, Ltd. Publications, New York, 2009, ISDN 978-0-470-74718-6.

[2] M. Kałuża B. Więcek Application of extension tubes in thermograpic measurements, Pomiary Automatyka Kontrola, vol. 55, no. 11, 2009.

[3] J. R. Howell, „Catalog of radiation configuration factors”, ed. Institute for Public Policy Research.

[4] R. Siegel, J.R. Howell, Thermal Radiation Heat Transfer, 3rd ed., Taylor and Francis, Hemisphere Publishing Corporation, ISBN 0-89116-271-2, 1992.

[5] E. Kostowski, Promieniowanie cieplne, PWN, Warszawa 1993, ISBN 83-01-10847-9 (in Polish)

[6] G. Gaussorgues, Infrared Thermography, Microwave Technology Series 5, Chapman and Hall, London, 1994. 